LA W RENCE LIVERMORE NATIONAL LABORATORY
Biomolecular Origin of The Rate-Dependent Deformation of Prismatic Enamel

Jikou Zhou, Luke Hsiung

July 10, 2006

Applied Physics Letters 
This document was prepared as an account of work sponsored by an agency of the United States Government. Neither the United States Government nor the University of California nor any of their employees, makes any warranty, express or implied, or assumes any legal liability or responsibility for the accuracy, completeness, or usefulness of any information, apparatus, product, or process disclosed, or represents that its use would not infringe privately owned rights. Reference herein to any specific commercial product, process, or service by trade name, trademark, manufacturer, or otherwise, does not necessarily constitute or imply its endorsement, recommendation, or favoring by the United States Government or the University of California. The views and opinions of authors expressed herein do not necessarily state or reflect those of the United States Government or the University of California, and shall not be used for advertising or product endorsement purposes. 


\title{
Biomolecular Origin of Rate-Dependent Deformation of Prismatic Enamel
}

\author{
Jikou Zhou and Luke L. Hsiung \\ Lawrence Livermore National Laboratory, Livermore, CA 94551
}

\begin{abstract}
Penetration deformation of columnar prismatic enamel was investigated using instrumented nanoindentation testing, carried out at three constant strain rates $\left(0.05 \mathrm{~s}^{-1}, 0.005 \mathrm{~s}^{-1}\right.$, and $0.0005 \mathrm{~s}^{-1}$ ). Enamel demonstrated better resistance to penetration deformation and greater elastic modulus values were measured at higher strain rates. The origin of the rate-dependent deformation was rationalized to be the shear deformation of nanoscale protein matrix surrounding each hydroxyapatite crystal rods. And the shear modulus of protein matrix was shown to depend on strain rate in a format: $G_{p}=0.213+0.021 \ln \dot{\varepsilon}$.
\end{abstract}

Most biological composites compromise reinforcement mineral components and an organic matrix. They are generally partitioned into multi-level to form hierarchical structures that have supreme resistance to crack growth [1]. The molecular mechanistic origin of toughness is associated with the "sacrificial chains" between the individual sub-domains in a protein molecule [2]. As the protein molecule is stretched, these "sacrificial chains" break to protect its backbone and dissipate energy [3]. Such fresh insights are providing new momentum toward updating our understanding of biological materials [4]. Prismatic enamel in teeth is one such material.

Prismatic microstructure is frequently observed in the surface layers of many biological materials, as exemplified in mollusk shells [5] and teeth [6]. It is a naturally optimized 
microstructure to bear impact loading and penetration deformation. In teeth, the columnar prismatic enamel provides mechanical and chemical protection for the relatively soft dentin layer. Its mechanical behavior and reliability are extremely important to ensure normal tooth function and human health. Since enamel generally contains up to 95\% hydroxyapatite (HAP) crystals and less than $5 \%$ protein matrix, it is commonly believed to be a weak and brittle material with little resistance to fracture [7].

This study is aimed at exploring the effect of the weak amelogenin-rich protein matrix on the overall mechanical behavior of prismatic enamel. The experimental work involves applying contact loads at various strain rates to carefully prepared enamel specimens using an instrumented nanoindentater. The enamel material and specimen preparation procedure were described in a previous study [8]. Briefly, the enamel was dissected into small blocks about 2 mm wide and $1 \mathrm{~mm}$ thick. These small blocks had relatively flat surfaces, under which the prisms were uniformly perpendicular to the top surfaces for nanoindentation testing [9.10]. The small blocks were then embedded, ground, and finishing polished with $0.03 \mu \mathrm{m}$ diamond suspension. Nanoindentation testing was carried out in a MTS XP® nanoindenter (MTS nano instrument, Oak Ridge, TN). Each test consisted of three segments, including a loading process, a holding period at the maximum load for a certain time, and a final unloading process. The loading process was carried out under constant strain rate [11] to reach a defined penetration depth, corresponding to which the maximum load was reached.

Three constant strain rates $\left(0.05 \mathrm{~s}^{-1}, 0.005 \mathrm{~s}^{-1}\right.$, and $\left.0.0005 \mathrm{~s}^{-1}\right)$ were used in this study. Corresponding to these were three sets of testing, each consisting of multiple tests with the same constant strain rate during loading process. Representative load-depth curves are shown in Figure 1. Corresponding to the same defined penetration depth of $400 \mathrm{~nm}$, as indicated by the vertical 
dash line, the maximum load levels strongly depended on the strain rates. At the lowest strain rate $0.0005 \mathrm{~s}^{-1}$, a maximum load of $11 \mathrm{mN}$ was required to make this penetration depth $(400 \mathrm{~nm})$. The load increased to $15 \mathrm{mN}$ at strain rate $0.005 \mathrm{~s}^{-1}$, and $17 \mathrm{mN}$ at the highest strain rate $0.05 \mathrm{~s}^{-1}$. The rising maximum load level with increasing strain rate indicates that enamel has better resistance to penetration deformation under a faster loading process.

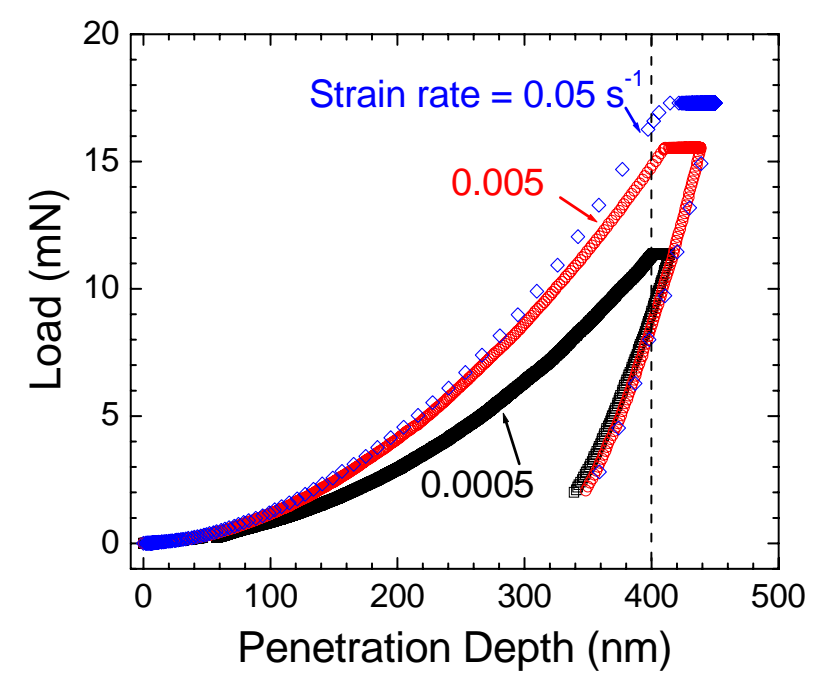

Figure 1: Representative load-depth curves corresponding to the three constant strain rates.

In the loading process, the elastic moduli were continuously measured using a continuous stiffness measurement (CSM) technique. This technique involves applying a very small force oscillation signal to the loading force at a high frequency, measuring the resulting displacement, and calculating the contact stiffness. CSM method enables us to continuously measure elastic and plastic parameters over a defined penetration depth. In the current study, the average value and standard deviation of the elastic modulus corresponding to each depth were calculated from the results of multiple indentation tests. The statistic values are plotted against indent depth in Figures 2. This figure contains several important points worth noting. First of all, elastic modulus 
decreases with increasing depth. This is consistent with a previous study [8], and may be attributed to the rotation of the HAP rods as penetration advances. It indicates that a meaningful elastic modulus value should be specified to the corresponding penetration depth. This is extremely important when we compare the mechanical properties obtained from different tests. Secondly, elastic modulus values measured at the lowest strain rate $\left(0.0005 \mathrm{~s}^{-1}\right)$ are significantly lower than those measured at higher strain rates. This phenomenon is yet to be understood. The final and most important point is that greater elastic modulus was measured at higher strain rate. This is true for each depth in the overall defined penetration depth (50 nm - $400 \mathrm{~nm}$ ).

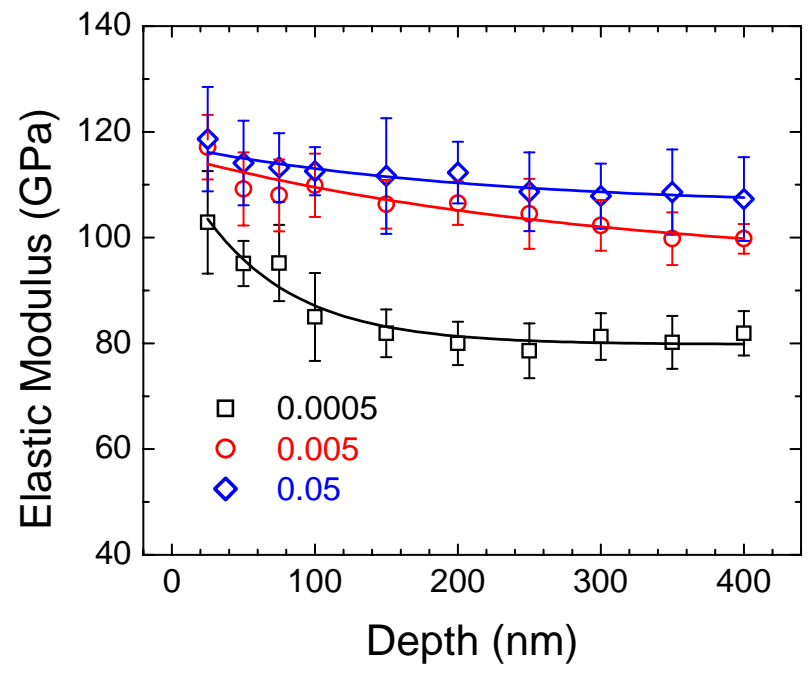

Figure 2: Elastic modulus of enamel measured under different strain rates.

Like other biological composites, enamel has microscale-to-nanocale hierarchical architecture. At a microsopic level, it consists of aligned prisms surrounded by an organic sheath. At the nanoscale level, each prism contains numerous HAP crystal rods that are separated by a nanometer-thin organic layer. The rod-like HAP crystals are about $50 \mathrm{~nm}$ in diameter, and oriented along the prism axis $[9,10]$. Such a structure is frequently treated as a unidirectional 
reinforced biocomposite, in which the HAP crystals are reinforcement fibers and the organic phase is the matrix [13]. From a mechanical point of view, its elastic modulus is a range with upper and lower bounds. The upper bound, $E_{e}^{u p}$, is given by the Voigt model, i.e. $E_{e}^{u p}=V_{h} E_{h}+V_{p} E_{p}$, in which $E$ is elastic modulus, $V$ is volume fraction, and subscripts $e, h$, and $p$ stand for enamel, hydroxyapatite, and protein, respectively. The lower bound is given by the Reuss model, i.e. $E_{e}^{\text {low }}=\frac{E_{p} E_{h}}{E_{p} V_{h}+E_{h} V_{p}}$. Cuy et al. [10] suggested that enamel close to the occlusal surface has about 95\% HAP crystal. The elastic modulus of HAP crystals in c-axis is 144 GPa [14]. The elastic modulus of the protein matrix is yet to be determined. But its effect may be evaluated by plotting modulus of enamel versus the shear modulus of protein matrix, $E_{p}$ (Figure 3). According to the Voigt model, the weak protein matrix carries negligible load, leading to nearly constant elastic moduli. The Reuss model gives almost zero estimates. The wide range between the upper and lower bounds provides no useful information to explain the ratedependent elastic modulus obtained in our experiment. The problem with these two models is that the protein matrix is treated merely as a load-bearing component.

Recent studies have suggested that the mechanical role of the protein matrix in biological composites goes beyond carrying load [1,15]. In response to applied loading, the protein matrix shears to transfer load between adjacent mineral components, and to accommodate deformation. This is incorporated into a tension-shear-chain (TSC) model to quantify the role of the aspect ratio of mineral tablets in determining the elastic modulus of a nacre [1]. We employ the TSC model to analyze the effect of protein matrix on the modulus of prismatic enamel. A necessary modification to the original model is to change the shape of the mineral component from polygon to cylinder. Following the same analysis [1], one obtains: $E_{e}=\frac{V_{h}^{2} E_{h} G_{p} \rho^{2}}{4\left(1-V_{h}\right) E_{h}+G_{p} V_{h} \rho^{2}}$, 
in which $\rho$ is the aspect ratio of HAP crystal rods (length to radius ratio), and $G_{p}$ is the shear modulus of protein matrix. All other parameters keep their usual definitions. The diameter of HAP crystal rod is about $50 \mathrm{~nm}$, the length is about $500-1000 \mathrm{~nm}$. This gives aspect ratios in a range of $20-40$. Taking a middle value, $\rho=30$, the elastic moduli of enamel versus shear modulus of protein matrix is plotted in Figure 3 as a symbol-line curve. The model estimates match very well with the experimental data in a range from 120 GPa to $80 \mathrm{GPa}$. Corresponding to this range, the shear modulus of protein matrix is between $\sim 0.05 \mathrm{GPa}$ and $\sim 0.23 \mathrm{GPa}$.

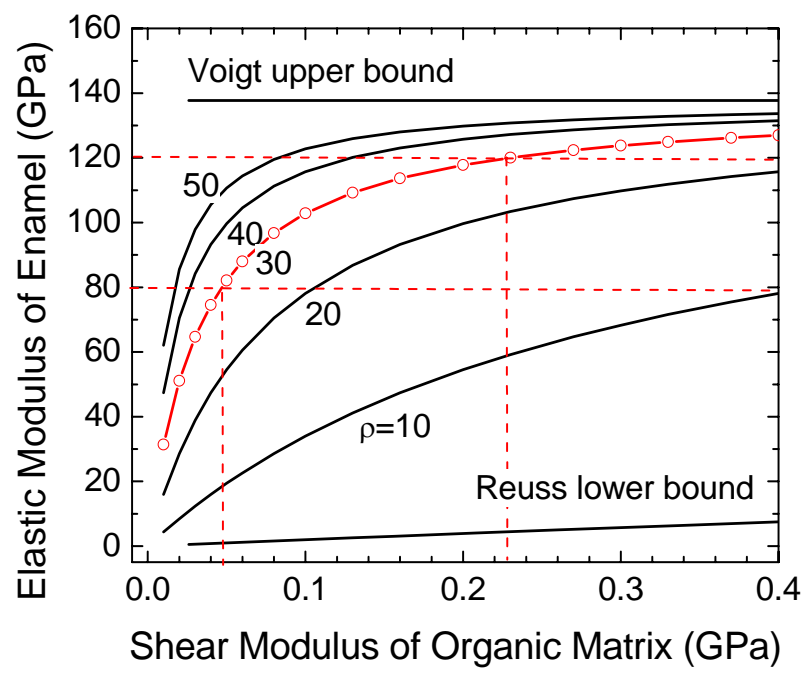

Figure 3: Comparison of experimental data and predictions made by the Viogt, Reuss, and TSC models; and the effects of the aspect ratio.

The HAP crystals may have various aspect ratios. Possible geometrical effects on the above relationship are evaluated by plotting elastic modulus of the biocomposite versus the shear modulus of the protein matrix using various values of aspect ratio (Figure 3). The plots show that the above relationship is valid over the possible range of aspect ratio in prismatic enamel (10-50). Moreover, the elastic modulus of the biocomposite is more sensitive when protein becomes weak, 
and sensitivity increases with increasing aspect ratio. These suggest that the mechanical properties of a biocomposite can be simply controlled by varying the aspect ratio. This provides important guidelines for making new biomaterials using a biomimetic approach $[5,16]$.

To quantitatively evaluate the shear modulus of the protein matrix from the experimentally measured elastic modulus values, we rewrite the latest equation in the following format: $G_{p}=\frac{4\left(1-V_{h}\right) E_{h} E_{e}}{\left(V_{h} E_{h}-E_{e}\right) V_{h} \rho^{2}}$. In the following estimation, we take $\rho=30, V_{h}=0.95$, and $E_{h}=144 \mathrm{GPa}$. Applying this equation, we calculate the shear moduli corresponding to the three strain rates over a penetration depth between $100 \mathrm{~nm}$ and $400 \mathrm{~nm}$, and plot them in Figure 4.

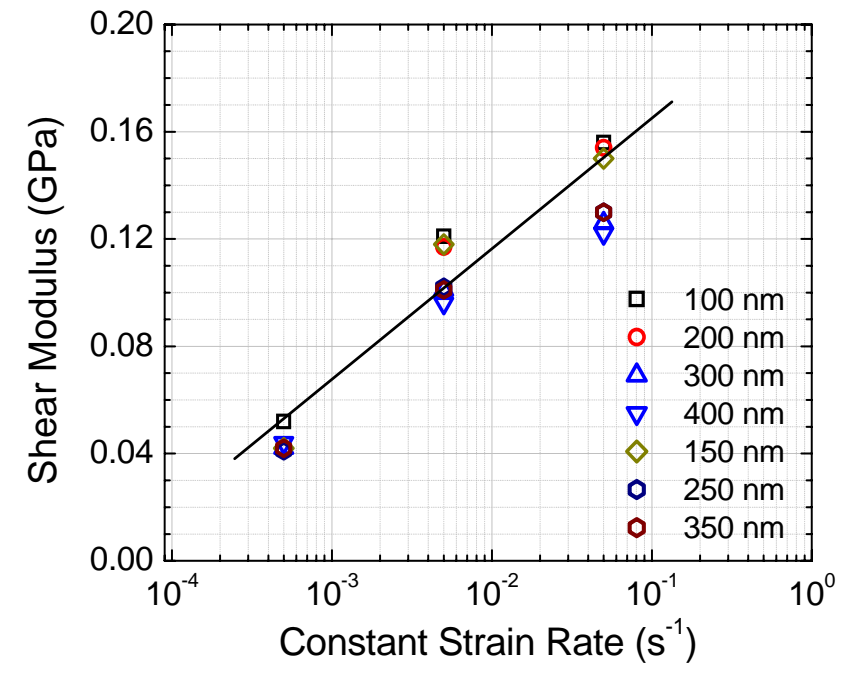

Figure 4: Dependence of the shear modulus of protein matrix on constant strain rate.

Protein matrix between HAP crystal rods is nanometer thin, and thus can be considered a single layer protein membrane. The stretching behavior of biological molecules has been intensively studied following the pioneering work by Rief et al. [17]. For molecules with twostage transition, the average unfolding force, $f$, required to break the sacrificial chains increases with stretching speed, $v$, following a simple relationship: $f=a+b \ln v$ [17], in which $a$ and $b$ 
are fitting constants. The shear deformation of the single layer of biomolecule is similar to the process of stretching individual biomolecules, and the force necessary to deform the layer is a summary of the forces required to stretch all the individuals [18]. The shear modulus of protein matrix, the summary of the forces required to stretch all biomolcules in a unit area by a unit length, should have a similar relationship with strain rate. This is attested to by a regression analysis of our experimental data. We obtain $G_{p}=0.213+0.021 \ln \dot{\varepsilon}$ (in GPa), in which $\dot{\varepsilon}$ is the strain rate. Unfortunately, there is no reported data in literature for comparison. In the above analysis, we did not consider the depth effect resulting from the microstructure evolution due to the interactions between nanoindenter tip and the prismatic microstructure. The data in Figure 4 indicates that they do not have significant effect on our analysis.

In summary, as the most mineralized and hardest tissue in the human body, prismatic enamel is commonly considered a brittle material. However, this study has shown unprecedentedly (to the authors' knowledge) that its deformation is dependent upon strain rate. Such rate dependence originates from the rate-dependent unfolding behavior of macromolecules in protein matrix. The rising elastic modulus and enhanced resistance to penetration deformation with increasing strain rate manifests the cleverness of nature in designing prismatic microstructure to bear impact loading at both fast and moderate loading speeds.

\section{Acknowledgement}

This work was performed under the auspices of the U. S. Department of Energy by the University of California, Lawrence Livermore National Laboratory under Contract No. W-7405Eng-48. The authors gratefully acknowledge to Dr. Amy Mao, Dr. John Kinney and Diane Rekow for stimulating discussion and providing enamel specimens. 


\section{References:}

1. H. Gao, B. Ji, I.L. Jäger, E. Arzt, and P. Fratzl, Proc. Natl. Acad. Sci. USA 100, 5597 (2003).

2. B.L. Smith, T.E. Schaeffer, M. Viani, J.B. Thompson, N.A. Frederick, J. Kindt, A. Belcher, G.D. Stucky, D.E. Morse, and P.K. Hansma, Nature 399, 761 (1999).

3. J.B. Thompson, J.H. Kindt, B. Drake, H.G. Hansma, D.E. Morse, and P.K. Hansma Nature 414, 773 (2001).

4. J.D. Currey, Proc. R. Soc. London. B 196, 443 (1977).

5. A.G. Checa, Al.B. Rodrígu z-Navarro, and F.J. Esteban-Delgado, Biomaterials 26, 6404 (2005).

6. B.R. Hairul Nizam, and C.T. Lim, J. Exp. Mech. 26, 487 (2006).

7. V. imbeni, J.J. Kruzic G.W. Marshall, S.J. Marshall, and R.O. Ritchie, Nat. Mater. 4, 229 (2005).

8. J. Zhou and L.L. Hsiung, . J. Biomed. Mater. Res. B. (in press).

9. H. Jiang, X-Y- Liu, C.T. Lim, and C.Y. Hsu, Appl. Phys. Lett. 86, 163901 (2005).

10. J.L. Cuy, A.B. Mann, K.J. Livi, M.F. Teaford, and T.P. Weihs, Arch. Oral. Biol.47, 281 (2002).

11. B.N. Lucas and W.C. Oliver, Metall. Mater. Trans. A 30, 601 (1999).

12. S. Habelitz, S.J. Marshall, G.W. Marshall, and M. Balooch, Arch. Oral. Biol. 46, 173 (2001).

13. I.R. Spears, J. Dent. Res. 76, 1690 (1997).

14. J.L. Katz, J. Biomech. 4, 455 (1971).

15. R.Z. Wang, Z. Suo, Z., A.G. Evans, N. Yao, and I.A. Aksay, J. Mater. Res. 16, 2485 (2001).

16. H.F. Chen, B.H. Clarkson, K. Sun, J.F. Mansfield, J. of Colloid. Interf. Sci. 288, 97 (2005).

17. M. Rief, M. Gautel, F.Oesterhelt, J.M. Fernandez, H. Gaub, Science 276, 1295 (1997). 
18. H.J. Qi1, C. Ortiz, and M.C. Boyce (in press).

\section{Figures:}

Figure 1: Representative load-depth curves corresponding to the three constant strain rates.

Figure 2: Elastic modulus of enamel measured under different strain rates.

Figure 3: Comparison of experimental data and predictions made by Viogt, Reuss, and TSC models, and the effects of aspect ratio.

Figure 4: Dependence of the shear modulus of protein matrix on constrain strain rate. 